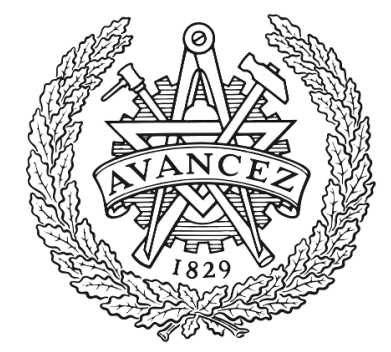

CHALMERS

UNIVERSITY OF TECHNOLOGY

\title{
Multiple electrical machines applied for high drive train efficiency
}

Downloaded from: https://research.chalmers.se, 2023-04-26 07:12 UTC

Citation for the original published paper (version of record):

Sharma, N., Liu, Y. (2019). Multiple electrical machines applied for high drive train efficiency. 2018 IEEE International Conference on Electrical Systems for Aircraft, Railway, Ship Propulsion and Road Vehicles \& International Transportation Electrification Conference (ESARS-ITEC). http://dx.doi.org/10.1109/ESARS-ITEC.2018.8607485

N.B. When citing this work, cite the original published paper. 


\title{
Multiple electrical machines applied for high drive train efficiency
}

\author{
Nimananda Sharma and Yujing Liu
}

\begin{abstract}
Conventionally, electric powertrain in battery electric vehicles are designed and optimized for a particular vehicle category and performance requirements. In this paper the design of an electric powertrain using two different type of machines is proposed with a focus on the design of electric machines. The powertrain is dimensioned by analyzing vehicle specifications, both combustion based and electric, vehicle performance requirements and wheel load analysis performed on simplified vehicle models using standard drive cycles. Two different vehicle models representing a small and medium size vehicle are used. To compare the distributed drive topology with two different machines, a third machine is designed to represent conventional electric powertrain. The proposed drive system is observed to achieve similar peak torque and power as the centralized drive using single machine. However, the proposed design of the powertrain resulted in slightly higher operating efficiency while providing a scalability of performance.
\end{abstract}

Index Terms-- Electric vehicles (EVs), motor drives, electric machine, permanent magnet machine, traction motor.

\section{INTRODUCTION}

$\mathrm{T}$ HE powertrain topology of current battery electric vehicle (BEVs) e.g. Nissan Leaf [1], Renault Zoe [2], Fiat 500e [3] etc. can be described as centralized drive comprising of one electric machine, power electronics and transmission including a single-speed reduction gear box and differential. Most of the BEVs are converted from internal combustion engine based vehicle (ICEV) models [4]. The powertrains design based on this topology are usually optimized to suit a particular vehicle application. Considering the limited number of mass market BEV models available today a centralized drive powertrain can be considered to be optimal [4]. However, as electric motor and power electronics size increases yielding higher peak power, it may be difficult to implement centralized drive without significantly changing the vehicle design. In such cases, it may be beneficial to use multiple drive units. An example is Tesla Model S dual motor configuration where a high performance motor is used on the rear shaft along with another motor on the front shaft [5]. This type of drive train topology is referred to as distributed drive [6].

According to [6], distributed drive topology can use inwheel motor or/and wheel-side motors to drive the wheels. The in-wheel motor designed concept have been demonstrated in the past and documented in literature [7] [9]. The in-wheel motor design is usually direct driven without gear reduction which can result in higher efficiency.

This project has received funding from the European Union's Horizon 2020 research and innovation programme under grant agreement No 769989. The opinions expressed in this document reflect only the author's view and reflects in no way the European Commission's opinions. The European Commission is not responsible for any use that may be made of the information it contains

The authors are with the Department of Electric Power Engineering, Chalmers University of Technology, Gothenburg 412 96, Sweden (e-mail: sharman@chalmers.se; yujing.liu@chalmers.se)
Also, wheel housing is used as motor housing resulting into a compact solution. However, it suffers from the problem of increased un-sprung mass which can negatively impact vehicle ride and handling performance. These motors also have low power and torque densities as a motor without speed reducing gear must produce very high torque in low speed region to support vehicle starting [6]. So, this study will consider wheel-side motor configuration.

The battery electric vehicles available today provide a fixed performance which may vary among vehicle manufacturers in terms of top speed and acceleration [4]. Unlike ICEVs, performance choices in terms of acceleration and top speed for same vehicle model are almost nonexistent for mass market BEVs. It can be attributed to the limited number of BEVs available in market. But, judging by increase in EV sale, it is safe to assume that the number of BEV models will be significantly higher in a decade resulting in the need for more performance options [4]. In case of ICEVs, the peak power can be increased by using turbochargers, superchargers etc. However, the peak power of an electric powertrain is limited by design e.g. size, thermal loading, converter rating etc. So, scalability in power can't be achieved in the same way as possible with combustion engine.

In this paper, a scalable electric powertrain design is proposed using combination of multiple drive units similar to distributed drive with a focus on the design of electric machines. Two different type of electric machine are considered: high efficiency and high power. A permanent magnet synchronous machine (PMSM) is used as high efficiency machine because of its lower rotor losses, high power and torque density which makes it a popular choice for traction motor in EV application. For high power, an electrically excited synchronous machine (EESM) is selected. The main advantages are no rare earth material, ability to control rotor flux independently which can result into better field weakening, no issues related to demagnetization and could be cheaper than PMSM. However, the rotor excitation in EESM requires additional converter and increases bill of material. The focus of this paper is to evaluate if EESM could be used to increase the overloading capability of an electric powertrain while using a reduced size PMSM as main traction machine.

\section{VEHICLE MODEL}

One dimensional vehicle model approximating the vehicle body as a rigid lumped mass around its center of gravity can be used to calculate the force on the wheel [10]. Considering only longitudinal vehicle motion, the force on the wheel can be calculated as

$$
F_{\text {wheel }}=\frac{\rho}{2} C_{d} A v^{2}+C_{r} m g \cos \alpha+m g \sin \alpha+m a
$$

where $F_{\text {wheel }}$ is the force on the wheels $(\mathrm{N}), \rho$ is air-density 
$\left(1.225 \mathrm{~kg} / \mathrm{m}^{3}\right), C_{d}$ is aero-dynamic drag co-efficient, $A$ (sq.m.) is effective cross-section area of the vehicle for drag, $v$ is vehicle speed $(\mathrm{m} / \mathrm{s}), g$ is acceleration due to gravity $(9.8$ $\left.\mathrm{m} / \mathrm{s}^{2}\right), C_{r}$ is co-efficient of rolling resistance of tires, $\theta$ is road gradient (rad) and $a$ is acceleration of the vehicle $\left(\mathrm{m} / \mathrm{s}^{2}\right)$. The maximum wheel force, $F_{\text {wheel }(\max )}$ that can be exerted on the driving wheel is limited by co-efficient of friction, $\mu$ between tire and road surface.

$$
F_{\text {wheel }(\max )}=\mu F_{\text {normal }}
$$

$F_{\text {normal }}$ is normal (to the road surface) component of the force acting on the driving wheel which depends on distribution of mass between front and rear axles of a vehicle. If the wheel force exceeds the maximum wheel force given by (2), the tires would slip. For the sake of simplicity, effect of wheel slip would be neglected [10].

A small and a medium size vehicles are modelled using the parameters described in [10] and are presented in Table I. The torque and power on wheels could be expressed as

$$
\begin{gathered}
T_{\text {wheel }}=F_{\text {wheel }} r_{\text {wheel }} \\
P_{\text {wheel }}=F_{\text {wheel }}{ }^{v}
\end{gathered}
$$

where $r_{\text {wheel }}$ is the wheel radius $(\mathrm{m})$. For an electric powertrain with single speed reduction gear with a final gear ratio of $k_{\text {gear }}$, the electric machine torque and speed can be calculated if the gear box efficiency is $\eta_{\text {gear }}$ as follows

$$
\begin{aligned}
T_{E M} & =\frac{T_{\text {wheel }}}{k_{\text {gear }} \eta_{\text {gear }}} \\
\omega_{\text {EM }} & =k_{\text {gear }} \frac{v}{r_{\text {wheel }}}
\end{aligned}
$$

where $T_{E M}$ is the electric machine torque $(\mathrm{Nm})$ and $\omega_{E M}$ in $\mathrm{rad} / \mathrm{s}$ is electric machine speed.

TABLE I

PARAmeters USED For Modelling a SMALl AND Medium Sized VEHICLE

\begin{tabular}{|l|l|l|}
\hline Vehicle parameters & Small & Medium \\
\hline Unladen/Curb weight $(\mathrm{kg})$ & 1200 & 1700 \\
\hline $\mathrm{C}_{\mathrm{d}}$ & 0.3 & 0.28 \\
\left.\hline${\text { Cross-section, } \mathrm{A}\left(\mathrm{m}^{2}\right)}\right)$ & 2.05 & 2.3 \\
\hline $\mathrm{C}_{\mathrm{r}}$ & 0.009 & 0.009 \\
\hline Wheel radius $(\mathrm{m})$ & 0.31 & 0.31 \\
\hline
\end{tabular}

\section{POWERTRAIN DIMENSIONING}

In order to dimension the powertrain, mainly peak and continuous rating of the electric machine, three different approaches were used. The performance requirements for the two vehicles were used along with vehicle specifications data of both ICEVs and BEVs. A comprehensive analysis of available BEVs specifications can be found in [10]. The basis for including ICEVs is to be able to compare specifications with BEVs. A wheel load analysis similar using vehicle model and standard drive cycle similar to one given in [10] is performed and is used to estimate requirements of real world driving assuming that the selected drive cycles are a good representation of the same.

\section{A. Specification of ICEVS and BEVS}

One challenge while collecting specifications of ICEVs is the number of available variants of same vehicle model

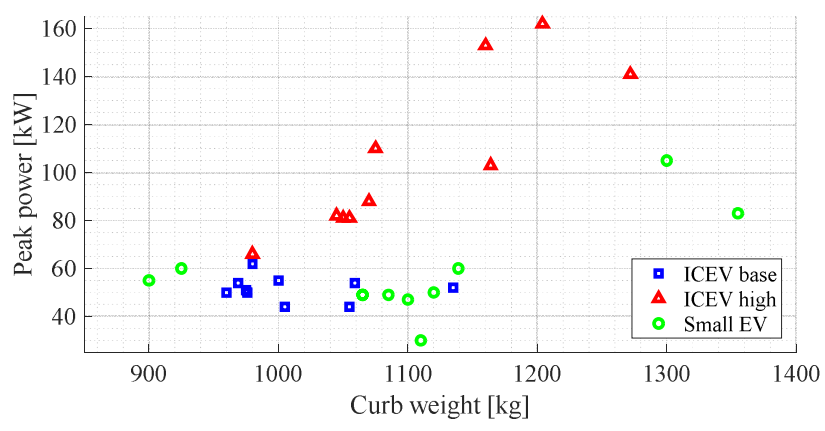

Fig 1: Peak power comparison of B segment ICEVs with small BEVs

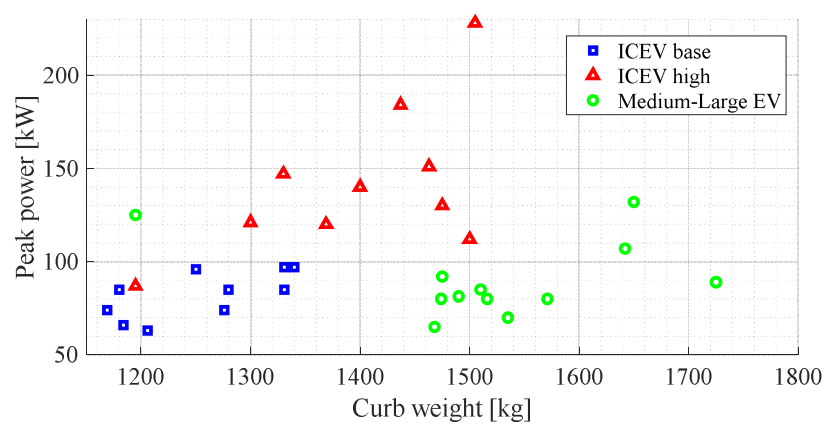

Fig. 2. Peak power comparison of $\mathrm{C}$ segment ICEVs with medium-large BEVs

which makes it difficult to compare the various vehicle models across manufacturers. So, following criteria were defined to select a variant to make uniform comparison and the selected variant is referred as base variant for the particular vehicle model.

1) Fuel Type: petrol.

2) Energy Converter: lowest power output compared to all the available variants of the same vehicle model.

3) Transmission Type: manual transmission with minimum number of speed reduction stages.

4) Vehicle Dimension: the variant with the smallest dimensions e.g. overall length etc.

5) Number of Doors: 5-door.

Similarly, another vehicle variant was selected as high variant having maximum power output of the ICE and quickest $0-100 \mathrm{~km} / \mathrm{h}$ acceleration time. The data of the selected vehicle models are presented in Appendix. The ICEVs are classified as $\mathrm{B}$ and $\mathrm{C}$ segment. The $\mathrm{B}$ segment ICEVs are compared to small BEVs as shown in Fig. 1. Fig. 2 presents the data of $\mathrm{C}$ segment ICEVs along with mediumlarge size BEVs.

It can be observed in Fig. 1 that the small BEVs and base variants of B segment ICEVs have similar peak power, approximately in the range $40-60 \mathrm{~kW}$. However, curb/unladen weight of the BEVs are comparatively higher compared to ICEVs in both Figs. 1 and 2. In Fig. 2, the peak power specifications are spread out with most of the BEVs and the base variant of ICEVs in the range of $60-100 \mathrm{~kW}$. The high variants of both $\mathrm{B}$ and $\mathrm{C}$ segment ICEVs help to understand the range of performance choices available for these type of vehicles. The peak power of such high variants vary quite a lot between manufacturers as observed in Figs. 1 and 2. Even though peak power of base variants of the ICEVs are comparable to BEVs, definitions of peak power for both type of energy converters is different. For EVs, peak power is often defined for a short period of time e.g. $30 \mathrm{sec}$ 
or 1 minute but are often constant over a wide range of rotational speed of electric machine which is also referred as constant speed range. But in case of ICEVs, it is defined for a particular rotational speed of the combustion engine and is not necessarily limited to a time duration.

\section{B. Performance requirements of $B E V S$}

The performance requirements considered in this study are acceleration, top speed and uphill driving. Acceleration and top speed specifications are usually published by manufacturers as part of the vehicle specifications and is available to public. The most common specification for acceleration performance is found to be $0-100 \mathrm{~km} / \mathrm{h}$ specified in seconds. However, the uphill driving capabilities of a vehicle are often not specified in the specifications. The performance requirements for the two type of vehicles used in this study are listed in Table II below [10]. The peak torque requirement often determined by acceleration performance depends on the base speed i.e. the speed till which the electric machine can produce peak torque followed by a constant power region. The base speed is approximated to be a third of the top speed of vehicle so as to have a compromise between the peak torque and peak power requirements and to limit the constant power speed ratio of the electric machine to 3 .

Using the performance specifications along with the vehicle model in section II, powertrain requirements of the two vehicles are estimated and presented in Table III. The final gear ratio, $k_{\text {gear }}$ of the gear box is calculated using maximum speed of the electric machine (12000 rev/min) and top speed of the vehicle given in Table II. The efficiency of the gear box is considered to be $95 \%$ and constant over the complete speed range. The continuous power of the powertrain is derived from top speed and uphill driving where the uphill driving requirement was found to be higher. However, since the continuous rating of the powertrain is defined for a longer time period e.g. 30 minutes, the uphill driving could still be considered as temporary overloading or peak requirements. It could be observed that the peak power requirements for both the small and medium size EVs are similar to vehicle specifications presented earlier in Figs. 1 and 2.

\section{Wheel load analysis of BEVs using drive cycle}

A wheel load analysis is performed to ascertain the requirements of powertrain with the assumption that the

TABLE II

PeRformanCe ReQuirement of SMAll AND Medium Size Vehicle

\begin{tabular}{|l|l|l|}
\hline Performance parameter & Small & Medium \\
\hline Base speed $(\mathrm{km} / \mathrm{h})$ & 45 & 50 \\
\hline Acceleration, $0-100 \mathrm{~km} / \mathrm{h} .(\mathrm{sec})$ & 13 & 10 \\
\hline Top speed $(\mathrm{km} / \mathrm{h}), v_{\max }$ & 135 & 150 \\
\hline Gradient driving $(\mathrm{km} / \mathrm{h}, \%)$ & 90,6 & 130,6 \\
\hline
\end{tabular}

TABLE III

POWERTRAIN REQUiREMENT FROM PERFORMANCE SPECIFICATION OF SMALL AND MEDIUM SIZE VeHICLE

\begin{tabular}{|l|l|l|}
\hline Powertrain requirement & Small & Medium \\
\hline Peak power $(\mathrm{kW}), 30 \mathrm{sec}$ & 55 & 93 \\
\hline Continuous power $(\mathrm{kW}), 30 \mathrm{~min}$ & 25 & 37 \\
\hline Gear ratio & 10.39 & 9.35 \\
\hline Peak torque of EM $(\mathrm{Nm}), 30 \mathrm{sec}$ & 122 & 222 \\
\hline
\end{tabular}

TABLE IV

MAXIMUM POWER AND TORQUE REQUIREMENT FOR A SMALl EV DURING Motoring AND GENERATING MODE IN WLTC DRIVE CYCLE

\begin{tabular}{|l|l|l|l|l|}
\hline \multirow{2}{*}{ WLTC phase } & \multicolumn{2}{|l|}{ Power $(\mathrm{kW})$} & \multicolumn{2}{l|}{ TEM $(\mathrm{Nm})$} \\
\cline { 2 - 5 } & Motor & Generator & Motor & Generator \\
\hline Low & 19.24 & 11.87 & 56.33 & 59.47 \\
\hline Medium & 26 & 23.31 & 67.6 & 59.12 \\
\hline High & 26.39 & 23.49 & 66.5 & 59.41 \\
\hline Extra high & 40.62 & 21 & 50.75 & 52.34 \\
\hline
\end{tabular}

TABLE V

MAXIMUM Power AND TORQUE REQUIREMENT FOR A MEDIUM SiZE EV During Motoring AND GENERATING Mode IN WLTC Drive CyCle

\begin{tabular}{|l|l|l|l|l|}
\hline \multirow{2}{*}{ WLTC phase } & \multicolumn{2}{|l|}{ Power $(\mathrm{kW})$} & \multicolumn{2}{l|}{$\mathrm{T}_{\mathrm{EM}}(\mathrm{Nm})$} \\
\cline { 2 - 5 } & Motor & Generator & Motor & Generator \\
\hline Low & 26.99 & 16.94 & 88.41 & 93.63 \\
\hline Medium & 35.71 & 33.51 & 105.8 & 93.22 \\
\hline High & 37.02 & 34.08 & 104.5 & 93.56 \\
\hline Extra high & 52.38 & 30.61 & 77.62 & 82.4 \\
\hline
\end{tabular}

requirements in Table III essentially indicate maximum capability of the powertrain and the most frequently used power and torque requirements are reflected by standardized drive cycle which is considered to represent actual driving. The Worldwide Harmonized Light Vehicles Test Cycle (WLTC) is used as the standardized drive cycle. The WLTC drive cycle has many different test cycles depending on the top speed and peak power to unladen mass ratio of the vehicle, the details of which could be found in [11]. In this work, the Class $3 \mathrm{~b}$ test cycle with $v_{\max } \geq 120 \mathrm{~km} / \mathrm{h}$ is considered. It consists of four phases: low, medium, high and extra high corresponding to the maximum speed during each phase. The efficiency of the gear box for the wheel load analysis is considered to be the same as before.

The maximum power and torque required from the electric machine to satisfy the selected WLTC drive cycle for a small and medium size EV is presented in Table IV and $\mathrm{V}$ respectively. For both vehicles, the speed of different phases in the drive cycle has larger impact on the power, a variation of almost $100 \%$ between low to extra high phase for both smaller and medium size EVs whereas the torque is mainly varying around $25 \%$ between the different drive cycle phases. The maximum power and torque required for a smaller EV is $75 \%$ and $55 \%$ respectively of the peak values captured in Table III. And, for a medium size EV, it is only $56 \%$ and $48 \%$ respectively. This means that the peak requirements defined by the specification is much higher compared to actual driving needs of the medium size vehicle. Also, it could be observed that the peak torque and power dimensioned for the smaller EV is sufficient to meet drive cycle requirements even for a medium size EV.

\section{ELECTRIC MACHINE}

It is observed that drive cycle requirements of both small and medium size EVs could be satisfied by the specification of small EV. So, both the small and medium size EVs can use PMSM as main traction machine whereas the EESM in medium size EV can be used to satisfy performance requirements and in some cases driving requirements which could not be fulfilled by the PMSM. In order to compare such a combination of two different machine, the stack length of the PMSM is scaled by $100 \%$ to obtain a third machine representing a centralized drive EV architecture 
with just one electric machine. The electromagnetic design is only considered e.g. the rotor topology of EESM may not be suitable for speed as high as $12000 \mathrm{rev} / \mathrm{min}$ and may require special consideration in wedge. However, this is not considered. Also, the thickness of magnet rib and bridges are kept close to reference values. The magnet rib and bridge thickness impacts the leakage flux but it is not considered as this will require detail mechanical simulation.

The parameters of the three machines are mentioned in Table VI. Both the PMSM and EESM in are designed with 8 pole and 48 slots and in distributed drive, they have the same outer dimension i.e. stator outer diameter and stack length. However, a larger air gap is used for the EESM due to higher rotor losses. The slip ratio i.e. stator inner to outer dimeter ratio is higher in EESM to compensate for the higher air gap. In EESM, slot area is reduced which is indicated by increase in tooth width and decrease in tooth height to increase flux and maximize torque production at the expense of phase resistance. The slot fill factor for the machines are shown in Table VI are calculated from ANSYS RMxprt assuming a wire wrap of $0.085 \mathrm{~mm}$ and is limited to $75 \%$. The rotor fill factor for the EESM is $72 \%$ and is calculated using the available area under the poles while accounting for wedge and using the wire wrap of $0.085 \mathrm{~mm}$. The total turns per pole in the field winding is 126 and the wire cross section is $0.861 \mathrm{~mm}$ and the field winding resistance is $10.8 \Omega$. Hitachi NEOMAX NMX-37F magnet is used in the PMSM with a thickness of $5.2 \mathrm{~mm}$ and width $15 \mathrm{~mm}$.

The cross-section of the three machines showing the flux density distribution is presented in Figs. 3 to 5 . The flux density distribution is shown for the peak torque and base speed operating point of the three machines. Figs. 3 and 5 are almost identical as they have same cross-section except for some slight difference in the stator flux density distribution which is mainly due to the different current angle. The maximum flux density in both teeth and yoke of the PMSM at $1.74 \mathrm{~T}$ and $1.78 \mathrm{~T}$ respectively are below the saturation flux density of $1.8 \mathrm{~T}$ of the iron SURA M250-35A. But, for the EESM the teeth are almost saturated as the flux density reaches $1.8 \mathrm{~T}$ whereas the yoke flux density is $1.73 \mathrm{~T}$. The

TABLE VI

PARAMETERS OF THE THREE DifFERENT TYPE OF MACHINE CASE 1: DISTRIBUTED DRIVE, CASE 2: CENTRALIZED DRIVE

\begin{tabular}{|l|l|l|l|}
\hline \multirow{2}{*}{ Machine parameters } & \multicolumn{2}{l|}{ Case 1 } & Case 2 \\
\cline { 2 - 4 } \multicolumn{2}{|l|}{ PMSM } & EESM & PMSM \\
\hline Dimensions (mm) & 175 & 175 & 175 \\
\hline Stator outer diameter & 120 & 126 & 120 \\
\hline Stator inner diameter & 0.8 & 1 & 0.8 \\
\hline Air gap & 100 & 100 & 200 \\
\hline Stack length & 8 & 8 & 8 \\
\hline No. of poles & 48 & 48 & 48 \\
\hline No. of slots & 4 & 4.8 & 4 \\
\hline Tooth width & 18.7 & 14.8 & 18.7 \\
\hline Tooth height & \multicolumn{2}{l}{} \\
\hline Winding & 6 & 5 & 3 \\
\hline No. of turns & 1 & 1 & 2 \\
\hline Number of strands & 8 & 8 & 8 \\
\hline No. of parallel branch & 1.085 & 0.965 & 1.085 \\
\hline Wire diameter & 73.5 & 72.7 & 73.5 \\
\hline Slot fill factor (\%) & 47.4 & 49.3 & 19.4 \\
\hline $\begin{array}{l}\text { Resistance per phase stator } \\
\text { winding (m } \Omega \text { ) }\end{array}$ & & & \\
\hline
\end{tabular}

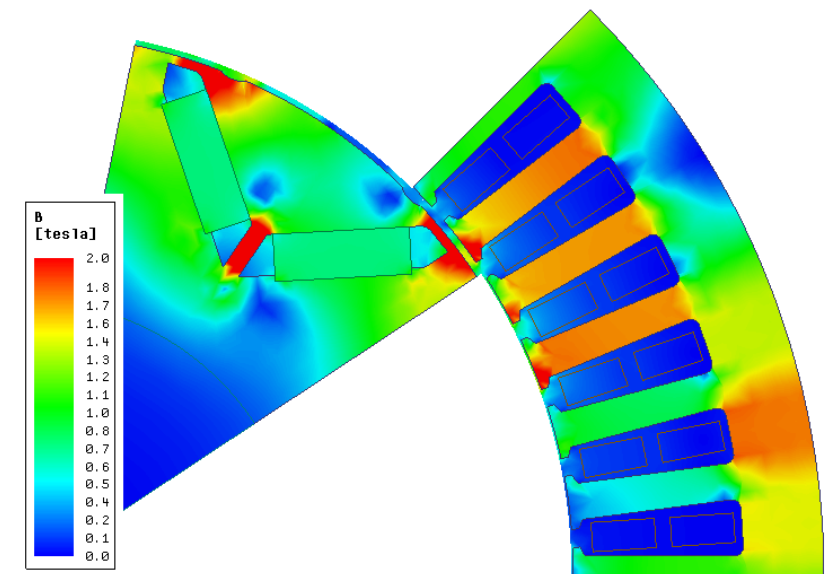

Fig. 3. Flux density distribution at peak load and base speed of distributed drive PMSM

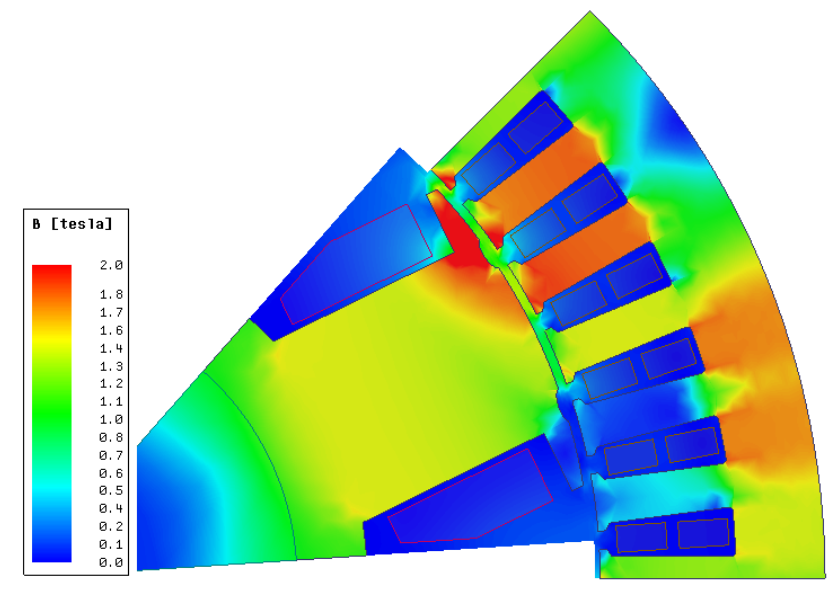

Fig. 4. Flux density distribution at peak load and base speed of distributed drive EESM

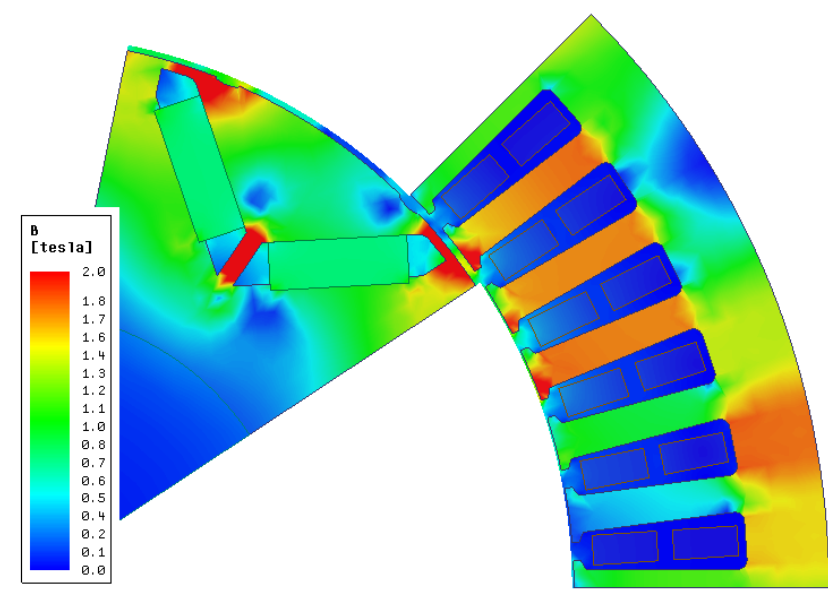

Fig. 5. Flux density distribution at peak load and base speed of centralized drive PMSM

peak air gap flux density of the PMSM and EESM are 1.5T and 1.4T respectively. The minimum flux density of the magnet is observed to be $0.6 \mathrm{~T}$ which can be considered safe until the temperature does not exceed $140^{\circ} \mathrm{C}[10]$.

The efficiency maps of the three machines are generated using FEM calculation of the three phase flux linkages and core losses. Then maximum torque per ampere control is used for finding the optimal d- and q-currents to produce a specific torque. In order to calculate efficiency map, the $\mathrm{Cu}$ loss, iron loss, mechanical and stray losses are considered. The $\mathrm{Cu}$ losses while using amplitude invariant transformation can be calculated as follows

$$
P_{C u}=\frac{3}{2} R_{S}\left(i_{d}^{2}+i_{q}^{2}\right)
$$




$$
P_{C u}=\frac{3}{2} R_{S}\left(i_{d}^{2}+i_{q}^{2}\right)+R_{f} i_{f}^{2}
$$

where $R s$ and $\mathrm{R}_{\mathrm{f}}$ are the per phase resistance of stator winding and field resistance of EESM in (ohm), $i_{d}, i_{q}$ and $i_{f}$ are d-, q- and field excitation current respectively. Equations (7) and (8) are used to obtain $\mathrm{Cu}$ losses for PMSM and EESM respectively. The core losses are first calculated using FEM calculations for a combination of current amplitude and current angle at base speed to generate a core loss map as a function of d- and q-current. Then, the core loss is calculated by interpolating the map at $\mathrm{d}$ - and q-current operating points. In order to scale the core loss for different speed and to include effects of punching of lamination material and harmonics in input of the electric machine, the following relationship is used

$$
P_{\text {core }}=\left(\frac{k_{h} \omega_{q}+k_{c} \omega_{q}^{2}}{k_{h} \omega_{b}+k_{c} \omega_{b}^{2}}\right) P_{\text {core }}^{\text {int } k_{\text {rot }} k_{\text {punch }}}
$$

where $P_{\text {core }}$ is core loss (W) at the query point, $P_{\text {core }}$ int $(\mathrm{W})$ is the interpolated core loss using the core loss map, $k_{h}$ and $k_{c}$ are hysteresis and eddy current co-efficient and are estimated from the iron material data sheet [12], $\omega_{b}$ is the electrical machine speed in (rev/min) at which the core loss map is generated using FEM calculation, $\omega_{q}$ is rotational speed of electric machine $(\mathrm{rev} / \mathrm{min})$ for which the core loss needs to be scaled up. The co-efficient $k_{\text {rot }}(1.05)$ and $k_{\text {punch }}(1.3)$ are to account for the increase in core loss due to the effect of harmonics and deterioration of iron material during punching of lamination sheets respectively. The mechanical and stray losses are approximated as follows

$$
\begin{gathered}
P_{\text {mech }}=\frac{5}{1000} P_{\text {peak }} \frac{\omega_{q}^{2}}{\omega_{\text {base }}^{2}} \\
P_{\text {stray }}=\frac{5}{1000} P_{\text {peak }} \frac{I_{s, q}^{2} \omega_{q}}{I_{s(\text { peak })}^{2} \omega_{\text {base }}}
\end{gathered}
$$

where $P_{\text {peak }}$ and $\omega_{\text {base }}$ are the peak power $(\mathrm{W})$ and base speed $(\mathrm{rev} / \mathrm{min})$ of the electric machine respectively, $I_{s(\text { peak })}$ is the amplitude of the stator current (A) needed to produce peak torque at base speed, $I_{s, q}$ and $\omega_{q}$ are query points for stator current amplitude (A) and rotation speed (rev/min) respectively.

The final performance of the three machines are presented in Table VII along with the torque-speed operating boundary

TABLE VII

Performance Parameters of THe Three Machine CASE 1: DISTRIBUTED DRIVE, CASE 2: CENTRALIZED DRIVE

\begin{tabular}{|l|l|l|l|}
\hline \multirow{2}{*}{ Machine parameters } & \multicolumn{2}{|l|}{ Case 1 } & Case 2 \\
\cline { 2 - 4 } & PMSM & EESM & PMSM \\
\hline DC link voltage (V) & 400 & 400 & 400 \\
\hline Peak rms current $(\mathrm{A})$ & 141 & 141 & 242 \\
\hline $\mathrm{J}\left(\mathrm{A} / \mathrm{mm}^{2}\right)$, peak & 19 & 24 & 19 \\
\hline $\mathrm{J}\left(\mathrm{A} / \mathrm{mm}^{2}\right)$, cont. & 10 & 10 & 10 \\
\hline Peak torque $(\mathrm{Nm})$ & 131 & 132 & 265 \\
\hline Cont. torque $(\mathrm{Nm})$ & 72 & 27 & 144 \\
\hline Base speed $(\mathrm{rev} / \mathrm{min})$ & 4000 & 4080 & 4000 \\
\hline Torque ripple $(\%)$ & 2.4 & 6.5 & 2.2 \\
\hline Peak power $(\mathrm{kW})$ & 55 & 56 & 111 \\
\hline Cont. power $(\mathrm{kW})$ & 30 & 11 & 60 \\
\hline Max. efficiency $(\%)$ & 95.5 & 93.1 & 95.9 \\
\hline
\end{tabular}

showing efficiency in Figs. 6 to 8. The DC link voltage is assumed at $400 \mathrm{~V}$ as mentioned in Table VII. The peak rms current is kept the same for distributed drive PMSM and EESM such that the same converter could be used to drive both the machines. The current density at $24 \mathrm{~A} / \mathrm{mm}^{2}$ for EESM is a little higher compared to PMSM but could be justified as EESM is mainly designed for overloading capability. The peak current density of rotor excitation is 20 $\mathrm{A} / \mathrm{mm}^{2}$ while the continuous is limited to $5 \mathrm{~A} / \mathrm{mm}^{2}$ to limit the rotor $\mathrm{Cu}$ losses. However, continuous stator current density is considered same for the three machine.

It could be observed in Table VII that peak torque and power of the distributed drive with the combination of the two machines are almost same as the scaled version used for centralized drive. However, the continuous power and torque capabilities of the distributed drive is limited by the EESM. This is due to the limitation of continuous current density in the rotor excitation. Torque ripple presented in Table VII is calculated at peak torque and base speed. Small ducts are used on rotor surface as seen in Figs. 3 to 5 to reduce air gap harmonics which result in lower torque ripple. The torque ripple of EESM even with the ducts is almost two times and is due to the rotor geometry. The torque ripple calculation

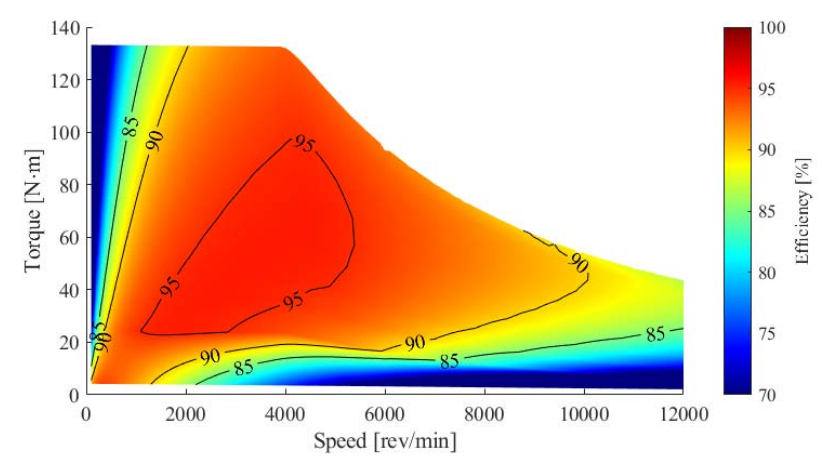

Fig. 6. Efficiency map of the distributed drive PMSM

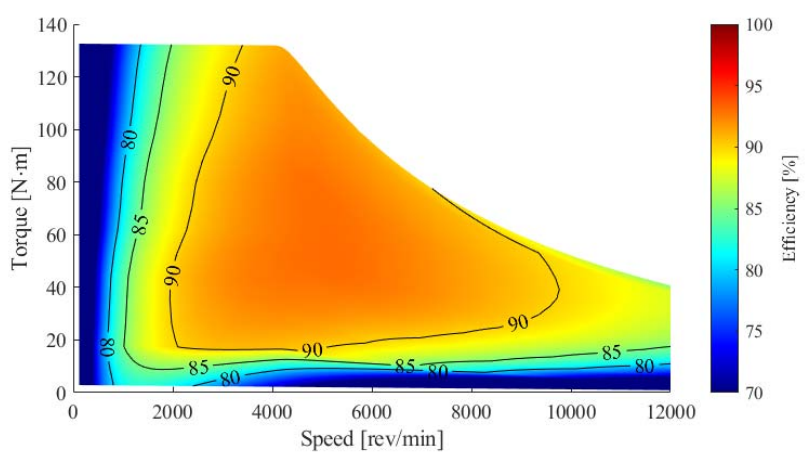

Fig. 7. Efficiency map of the distributed drive EESM

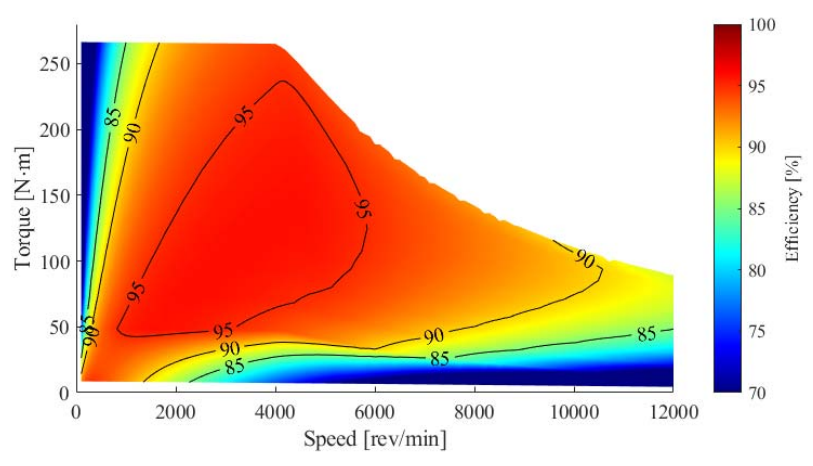

Fig. 8. Efficiency map of the centralized drive PMSM 
does not consider the effect of skewing. The efficiency of the EESM is slightly inferior compared to the PMSM in Figs. 6 and 7. It can be observed that in low speed and lower torque the PMSM has better efficiency whereas in high speed region both the PMSM and EESM have very similar efficiencies. The centralized PMSM in Fig. 8 has slightly higher efficiency with peak efficiency almost reaching 96\%. The peak efficiency of the EESM reaches $93.1 \%$ which could be considered acceptable.

\section{COMPARISON OF THE TWO DRIVE SYSTEMS}

The efficiency maps of the three machines is then used along with vehicle model and WLTC drive cycle to calculate the average operating efficiencies of the two different drive systems and compared. The average efficiency is calculated as a ratio of wheel energy to the total input energy accounting for losses in electric machine and gear box whose efficiency is assumed at $95 \%$. In Table VIII the results are presented where case 1 indicates a drive system with distributed drive PMSM and EESM and case 2 containing only centralized drive PMSM. It is assumed that the EESM is used with a one-way clutch which means that there will be no mechanical losses in the EESM when it is not used. Also, a simple torque splitting is used to distribute demanded torque from the wheels between the two machines in distributed drive in order to select optimal operating point for the two machines.

It can be observed from Table VIII, that the operating efficiencies of both the drive systems are lower compared to the peak efficiencies observed in Figs. 6 to 8 with distributed drive performing little better for low phase of the drive cycle in both small and medium size EV. The centralized drive PMSM has lower operating efficiencies when used in a small $\mathrm{EV}$ which indicates that it is over dimensioned for small EV application and a noticeable improvement is observed when used with a medium size EV. So, using the centralized drive PMSM in small EV could provide a performance boost but at the cost of operating efficiency. Interestingly, the distributed drive with the combination of PMSM and EESM performs better than the centralized drive PMSM for both the small and medium size EV. Even with a medium size car, the gain in efficiency is from 2 to $7 \%$. This is because, the distributed drive PMSM is dimensioned appropriately to support the driving requirements of both the small and medium size EV.

\section{CONCLUSION}

The wheel load analysis performed using the standardized drive cycle resulted in much lower demand especially for the medium size vehicle compared to the maximum capability needed to meet acceleration requirements. So, instead of

\section{TABLE VIII}

Average EfFiciency (\%) OF THE Two Drive Systems For SMALl AND MEDIUM SizE EV IN WLTC DRIVE CYCLE

CASE 1: DISTRIBUTED DRIVE, CASE 2: CENTRALIZED DRIVE

\begin{tabular}{|l|l|l|l|l|}
\hline \multirow{2}{*}{ WLTC phase } & \multicolumn{2}{|l|}{ Small } & Medium \\
\cline { 2 - 5 } & Case 1 & Case 2 & Case 1 & Case 2 \\
\hline Low & 93.3 & 89.6 & 93.8 & 91.3 \\
\hline Medium & 91.4 & 86 & 92.7 & 89.5 \\
\hline High & 87.7 & 80 & 89.7 & 85.1 \\
\hline Extra High & 85.81 & 77.5 & 89.1 & 82.7 \\
\hline
\end{tabular}

over dimensioning the powertrain to meet the performance requirements, the distributed drive approach with two different machines seemed fair as similar peak performance could be achieved. The operating efficiencies of the powertrain with the distributed approach was also found to be higher than using a single machine as in centralized drive. As observed in the wheel load analysis, the driving load for both vehicles could be satisfied with the distributed drive PMSM and so the operating efficiency improved as the machine was better dimensioned for handling the driving load of the selected drive cycle. It shows that the combination of PMSM and EESM could indeed be interesting for electric vehicles if the PMSM is designed to handle driving load and EESM to increase the peak torque. Also, combination of the two machines in distributed drive could be cheaper considering only half of the magnet quantity was required and it may be possible to use the same converter for the two machines. The analysis could also be extended to include various vehicle applications in future e.g. performance, commercial etc.

\section{APPENDIX}

The specification data of the selected ICEVs are presented in Table IX and Table X. The curb weight and power along with the selected vehicle variants are presented. All the vehicle data is collected from manufacturers specifications e.g. brochure. The selected vehicle model variant and ICE variant is also presented. The specification data is collected from the UK market. The curb weight declared by some manufacturers explicitly mentions the loading conditions e.g. driver, passenger, fuel tank etc. while for others it may not be the case. Also, for some vehicle models the curb weight is mentioned in a range. In such cases the minimum value of the range is considered. The

TABLE IX

Vehicle Specification Data of Base Variant of B Segment Icevs [13] - [22]

\begin{tabular}{|c|c|c|c|c|}
\hline Manufacturer & Model & Variants & Curb & Power \\
\hline Renault & Clio & Expression & 1059 & 54 \\
\hline Volkswagen & Polo & S & 1055 & 44 \\
\hline Ford & Fiesta & Style & 1135 & 52 \\
\hline Opel & Corsa & Sting & 1000 & 55 \\
\hline Peugeot & 208 & Active & 960 & 50 \\
\hline Dacia & Sandero & Access & 969 & 54 \\
\hline Citroen & C3 & Touch & 976 & 50 \\
\hline Toyota & Yaris & Active & 975 & 51 \\
\hline Skoda & Fabia & Hatch S & 1005 & 44 \\
\hline Hyundai & i20 & SE & 980 & 62 \\
\hline
\end{tabular}

TABLE X

Vehicle Specification Data of Base Variant of C Segment ICEVS [23] - [32]

\begin{tabular}{|c|c|c|c|c|}
\hline Manufacturer & Model & Variants & Curb & Power \\
\hline Volkswagen & Golf & S & 1206 & 63 \\
\hline Nissan & Qashqai & Visia & 1331 & 85 \\
\hline Renault & Captur & Expression+ & 1184 & 66 \\
\hline Opel & Astra & Design & 1169 & 74 \\
\hline Ford & Focus & Zetec & 1276 & 74 \\
\hline Renault & Megane & Expression+ & 1340 & 97 \\
\hline Audi & A3 & SE & 1180 & 85 \\
\hline Peugeot & 3008 & Active & 1250 & 96 \\
\hline Opel & Mokka X & Design Nav & 1280 & 85 \\
\hline Hyundai & Tucson & S & 1331 & 97 \\
\hline
\end{tabular}


vehicle variants considered 'for selecting base and high end variants only constitute of the available petrol variants so as to have a uniformity in specifications. The high end variants data are not included but the criteria for selecting high end variants is mainly: 5 door variants, highest power of ICE and fastest $0-100 \mathrm{~km} / \mathrm{h}$. acceleration. The data for small and medium-large size BEVs can be found in [4].

\section{REFERENCES}

[1] "Nissan Leaf", accessed 2018-02-01. [Online]. Available: https://www.nissan.co.uk/vehicles/new-vehicles/leaf.html

[2] "Renault Zoe", accessed 2018-02-01. [Online]. Available: https://www.renault.co.uk/vehicles/new-vehicles/zoe-250.html html

[3] "Fiat 500e", accessed 2018-02-01. [Online]. Available: https://www.fiatusa.com/gab.html

[4] E. A. Grunditz and T. Thiringer, "Performance Analysis of Current BEVs Based on a Comprehensive Review of Specifications," in IEEE Transactions on Transportation Electrification, vol. 2, no. 3, pp. 270289, Sept. 2016.

[5] "Tesla Model S", accessed 2018-02-01. [Online]. Available: https://www.tesla.com/en_EU/models?redirect=no

[6] X. Chen, Cheng Gu, Jun Yin, F. Tang and Xinjian Wang, "An overview of distributed drive electric vehicle chassis integration," 2014 IEEE Conference and Expo Transportation Electrification Asia-Pacific (ITEC Asia-Pacific), Beijing, 2014, pp. $1-5$.

[7] M. Terashima, T. Ashikaga, T. Mizuno, K. Natori, N. Fujiwara and M. Yada, "Novel motors and controllers for high-performance electric vehicle with four in-wheel motors," in IEEE Transactions on Industrial Electronics, vol. 44, no. 1, pp. 28-38, Feb 1997.

[8] Johnston D. "TM4 Motor-Wheel Drive and Control System: Performance, Benefits and Advantages", Proceedings of the 17th International Electric Vehicle Symposium, Montreal, Canada, 2000

[9] H. Shimizu, J. Harada, C. Bland, K. Kawakami and L. Chan, "Advanced concepts in electric vehicle design," in IEEE Transactions on Industrial Electronics, vol. 44, no. 1, pp. 14-18, Feb 1997.

[10] E. A. Grunditz, "Design and Assessment of Battery Electric Vehicle Powertrain, with Respect to Performance, Energy Consumption and Electric Motor Thermal Capability," Ph.D. thesis, Dept. Electric Power. Eng., Chalmers Univ., Gothenburg, 2016.

[11] Worldwide harmonized Light Vehicles Test Procedure, Addendum 15: Global technical regulation No. 15. [Online]. Available: https://www.unece.org/fileadmin/DAM/trans/main/wp29/wp29r1998agr-rules/ECE-TRANS-180a15e.pdf

[12] SURA M235-35A, Cogent Power, [Online]. Available: https://cogentpower.com/cms-data/downloads/m235-35a.pdf

[13] "Renault Clio “, accessed 2018-02-01. [Online]. Available: https://www.renault.co.uk/vehicles/new-vehicles/new-clio.html

[14] "Volkswagen Polo", accessed 2018-02-01. [Online]. Available: http://www.volkswagen.co.uk/new/polo-nf

[15] "Ford Fiesta", accessed 2018-02-01. [Online]. Available: https://www.ford.co.uk/vehicles/new-fiesta

[16] "Opel Corsa", accessed 2018-02-01. [Online]. Available: http://www.vauxhall.co.uk/vehicles/vauxhall-range/vehicles/corsarange/index.html

[17] "Peugeot 208", accessed 2018-02-01. [Online]. Available: http://www.peugeot.co.uk/showroom/208/5-door/

[18] "Dacia Sandero", accessed 2018-02-01. [Online]. Available: https://www.dacia.co.uk/vehicles/our-range/sandero.html

[19] "Citroen C3", accessed 2018-02-01. [Online]. Available: $\mathrm{http}: / /$ www.citroen.co.uk/new-vehicles-and-vans/citroenrange/citroen-c3

[20] "Toyota Yaris", accessed 2018-02-01. [Online]. Available: https://www.toyota.co.uk/new-vehicles/yaris/index json

[21] "Skoda Fabia", accessed 2018-02-01. [Online]. Available: http://www.skoda.co.uk/models/fabia-hatch

[22] "Hyundai i20", accessed 2018-02-01. [Online]. Available: https://www.hyundai.co.uk/new-vehicles/i20

[23] "Volkswagen Golf", accessed 2018-02-01. [Online]. Available: http://www.volkswagen.co.uk/new/golf-vii-pa

[24] "Nissan Qashqai", accessed 2018-02-01. [Online]. Available: https://www.nissan.co.uk/vehicles/new-vehicles/qashqai.html

[25] "Renault Captur", accessed 2018-02-01. [Online]. Available: https://www.renault.co.uk/vehicles/new-vehicles/new-captur.html

[26] "Opel Astra", accessed 2018-02-01. [Online]. Available: http://www.vauxhall.co.uk/vehicles/vauxhall-range/vehicles/newastra/overview.htm
[27] "Ford Focus", accessed 2018-02-01. [Online]. Available: https://www.ford.co.uk/vehicles/focus

[28] "Renault Megane", accessed 2018-02-01. [Online]. Available: https://www.renault.co.uk/vehicles/new-vehicles/megane.html

[29] "Audi A3", accessed 2018-02-01. [Online]. Available: https://www.audi.co.uk/explore-models/explore-by-range/a3.html

[30] "Peugeot 3008", accessed 2018-02-01. [Online]. Available: http://www.peugeot.co.uk/showroom/3008/suv/

[31] "Opel Mokka X", accessed 2018-02-01. [Online]. Available: http://www.vauxhall.co.uk/vehicles/vauxhall-range/vehicles/mokka$\mathrm{x} /$ overview.html

[32] "Hyundai Tucson", accessed 2018-02-01. [Online]. Available: https://www.hyundai.co.uk/new-vehicles/tucson

\section{BIOGRAPHIES}

Nimananda Sharma received his undergraduate degree in Electrical Engineering from National Institute of Technology Silchar, India on 2011. He did his Master's degree in Electric Power Engineering from Chalmers University of Technology in Gothenburg, Sweden where he is currently pursuing his $\mathrm{PhD}$. He is working on a project named DRIVEMODE, a technology development project related to distributed drive system for electric vehicles funded by the European Commission under Horizon 2020 framework.

Yujing Liu received B.Sc., M.Sc. and Ph.D. degrees in electrical engineering from Harbin Institute of Technology, Harbin, China, in 1982, 1985, and 1988, respectively. In 1996-2013, he worked in ABB Corporate Research, Våsterås, Sweden. Since 2013, he is professor on electrical power engineering in Chalmers University of Technology. Gothenburg, Sweden. His interest includes research on motors, converters, and wireless charging for electric vehicles, generators and power electronics for tidal power conversion, and high efficiency machines for energy saving in industrial applications. Yujing Liu is senior IEEE member and member in Swedish Standard Committee on Electrical Machines. 